\title{
Sarampo no Nordeste: análise da cobertura vacinal e dos casos confirmados de 2016 a 2020
}

\author{
Measles in the Northeast: analysis of vaccination coverage and confirmed cases from \\ 2016 to 2020
}

Sarampión en el Nordeste: análisis de cobertura de vacunación y casos confirmados de 2016 a 2020

Claudia Alves dos Santos Lopes ${ }^{1 *}$, Fernanda de Oliveira Souza ${ }^{2}$, Deisy Vital dos Santos ${ }^{2}$, Graziele Santos Santana Bomfim³.

\section{RESUMO}

Objetivo: Descrever a Cobertura Vacinal (CV) do sarampo, e a frequência de casos confirmados na região nordeste de 2016 a 2020. Métodos: Trata-se de um estudo descritivo, com análise quantitativa, por meio de dados secundários. A coleta de dados da CV e do monitoramento rápido de cobertura vacinal (MRC) foi realizada no SIPNI, enquanto os casos confirmados de sarampo e óbito foram extraídos do e-SIC e dos boletins epidemiológicos. Resultados: A CV de sarampo no Nordeste (2016 - 2020) encontra-se abaixo do esperado na rotina, tanto D1 e D2. No MRC de 1 a 4 anos, apenas as idades de 2 a 3 anos alcançou a meta de $95 \%$. O número de casos de sarampo foi mais expressivo no ano de 2019, com um total de 268 casos. Em relação aos casos confirmados, não houve interferência direta com a CV, pois no ano de 2016 e 2017 as coberturas estavam abaixo do preconizado e, no entanto, não houve registro de nenhum caso. Acredita-se que houve falha na tabulação dos dados da cobertura. Conclusão: Observa-se que a CV com o componente sarampo esteve aquém do proposto pela OMS no Nordeste. Sugere-se revisão das coberturas e medidas de controle do vírus.

Palavras-chave: Sarampo, Cobertura vacinal, Programa de imunização.

\begin{abstract}
Objective: To describe the Vaccination Coverage (VC) of measles, and the frequency of confirmed cases in the Northeast region from 2016 to 2020. Methods: This is a descriptive study, with quantitative analysis, using secondary data. Data collection on VC and rapid monitoring of vaccination coverage (CRM) was performed at SIPNI, while confirmed cases of measles and death were extracted from e-SIC and epidemiological bulletins. Results: The CV of measles in the Northeast $(2016-2020)$ is lower than expected in the routine, both D1 and D2. In the 1 to 4 year CRM, only ages 2 to 3 years reached the $95 \%$ target. The number of measles cases was most significant in 2019, with a total of 268 cases. Regarding confirmed cases, there was no direct interference with the VC, as in 2016 and 2017 the coverage was below what was recommended and, however, there was no record of any case. It is believed that there was a failure in the tabulation of coverage data. Conclusion: It is observed that the VC with the measles component was below that proposed by the WHO in the Northeast. It is suggested that coverage and virus control measures be reviewed.
\end{abstract}

Keywords: Measles, Vaccine coverage, Immunization program.

1 Secretaria Municipal de Saúde, Salvador - BA. *E-mail: claudia.alves7@yahoo.com.br

2 Universidade Federal do Recôncavo da Bahia (UFRB), Santo Antônio de Jesus - BA.

${ }^{3}$ Faculdade de Ciências e Empreendedorismo (FACEMP), Santo Antônio de Jesus - BA. 


\section{RESUMEN}

Objetivo: Describir la Cobertura de Vacunación (CV) de sarampión y la frecuencia de casos confirmados en la región Nordeste de 2016 a 2020. Métodos: Se trata de un estudio descriptivo, con análisis cuantitativo, utilizando datos secundarios. En el SIPNI se realizó la recolección de datos sobre CV y el monitoreo rápido de la cobertura de vacunación (CRM), mientras que los casos confirmados de sarampión y muerte se extrajeron del e-SIC y de los boletines epidemiológicos. Resultados: EI CV del sarampión en el Nordeste (2016 - 2020) es menor de lo esperado en la rutina, tanto D1 como D2. En el CRM de 1 a 4 años, solo las edades de 2 a 3 años alcanzaron el objetivo del 95\%. El número de casos de sarampión fue más significativo en 2019, con un total de 268 casos. En cuanto a los casos confirmados, no hubo interferencia directa con la CV, ya que en 2016 y 2017 la cobertura estuvo por debajo de lo recomendado y, sin embargo, no se registró ningún caso. Se cree que hubo una falla en la tabulación de los datos de cobertura. Conclusión: Se observa que la CV con el componente de sarampión estuvo por debajo de la propuesta por la OMS en el Nordeste. Se sugiere revisar la cobertura y las medidas de control de virus.

Palabras clave: Sarampión, Cobertura de vacunas, Programa de inmunizaciones.

\section{INTRODUÇÃO}

No âmbito do Sistema Único de Saúde (SUS), a Política Nacional de Atenção Integral à Saúde da Criança (PNAISC) indica ações programáticas para que seja garantido o pleno desenvolvimento da criança nas diferentes etapas do ciclo de vida, com especial atenção na promoção da saúde, prevenção de doenças e agravos, assistência e reabilitação relacionada à saúde (MINISTÉRIO DA SAÚDE, 2015). Dentre as ações de prevenção de doenças e agravos sabe-se que a imunização na infância é uma das maneiras mais eficazes de prevenir a ocorrência de certas doenças, tendo reduzido significativamente a mortalidade associada às doenças infecciosas em todo o mundo, durante as últimas décadas (OPAS, 2021).

O Brasil possui o Programa Nacional de Imunização (PNI), que foi criado em 1973, com intuito de combater, controlar e erradicar as doenças imunopreviníveis. Dentre as vacinas disponíveis, está a vacina contra o sarampo, introduzida no calendário nacional de imunização desde 1960. Atualmente é disponibilizado na rede pública três tipos de vacina contra o sarampo, dentre elas estão a Dupla Viral (DV) que protege contra sarampo e rubéola, a Tríplice Viral (TV) que protege com sarampo, caxumba e rubéola e a Tetra Viral que protege contra sarampo, caxumba, rubéola e varicela (MINISTÉRIO DA SAÚDE, 2018; MINISTÉRIO DA SAÚDE, 2019).

O sarampo é uma doença infecciosa exantemática aguda, causado por um vírus da família paramyxorividae. A sua transmissão de dá por contato direto entre indivíduos infectados pelo vírus, por meio das secreções do nariz ou da garganta infecionada. Assim, considerando a sua alta capacidade de contágio, antes do desenvolvimento de vacina específica contra a doença, ocorriam aproximadamente 2,6 milhões de óbitos por ano (OPAS, 2021).

A infecção viral atinge o sistema respiratório e caracteriza-se por febre alta (acima de $38,5^{\circ} \mathrm{C}$ ) (OPAS, 2019). As formas mais graves da doença são a pneumonia e a encefalite, que pode levar ao óbito, principalmente em crianças desnutridas, as que não foram imunizadas com o componente sarampo e as que vivem nos países em desenvolvimento como o Brasil (MINISTÉRIO DA SAÚDE, 2019).

Para controlar a transmissão do sarampo é necessário que a população esteja devidamente vacinada de acordo com a faixa etária, a saber: criança de 12 meses administra a primeira dose (D1) da tríplice viral; aos 15 meses a tetra viral ou a segunda dose (D2) da tríplice; os indivíduos não vacinados na infância que estejam entre 20 a 29 anos imuniza-se a D1 com intervalo de 30 dias a D2; enquanto que pessoas de 30 a 59 anos devem tomar uma dose única da vacina, já para profissionais de saúde será necessário duas doses da vacina independentemente da idade (BRASIL, 2018).

Em 2019 devido ao aumento dos casos e alta transmissibilidade do vírus o PNI instituiu a dose (D0) para as crianças de 6 meses até os 11 meses e 29 dias para aquelas que fossem viajar para a área em situação 
de surto, vale lembrar que a vacina nesta idade não é válida para o calendário nacional de vacinação como cobertura vacinal devendo seguir o esquema de rotina vacinal para o sarampo (MINISTÉRIO DA SAÚDE, 2019).

Salienta-se que após a introdução dessa vacina foram implantadas ações de vigilância epidemiológica bem-sucedidas na população, tais como: as campanhas de vacinas, contenção de surto de sarampo através de bloqueio vacinal, basca ativa de crianças faltosos, o que contribuiu para o país receber o certificado de eliminação da circulação do vírus Sarampo pela Organização Mundial de Saúde (OMS) em 2016. No entanto, em 2018 o Brasil voltou a apresentar casos de sarampo importados, perdendo assim a certificação nesse mesmo ano (CHAVES ERC et al., 2019; DOMINGUES CMAS, et al., 2019; RODRIGUES BLP, et al., 2020).

De acordo com a OPAS no ano de 2019 foram confirmados mais de 15 mil casos da doença e dentre os países com maiores números de casos estava o Brasil com 13.489 casos, seguido dos Estados Unidos com 1.276 e Venezuela com 552 (OPAS, 2019). No Nordeste do Brasil, ocorreram 70 casos da doença em 2020 e um estudo realizado por Pacheco FC, et al. (2019) observaram que ao longo do tempo todos os estados da região Nordeste apresentaram quedas significativas na cobertura vacinal para o sarampo (MINISTÉRIO DA SAÚDE, 2020).

Nesse contexto, tem-se o monitoramento rápido de cobertura vacinal (MRC), cujo objetivo é subsidiar as ações de imunização e traçar metas baseadas na realidade de cada local. A sua realização apresenta-se como vantagem para a vacinação dos indivíduos susceptíveis, identificação da cobertura real em curto período, além de possibilitar o conhecimento das lacunas e motivos apresentados pelos pais/responsáveis pela não vacinação dos filhos (MINISTÉRIO DA SAÚDE, 2018).

Logo o objetivo deste estudo foi descrever a cobertura vacinal do sarampo, e a frequência de casos confirmados na região nordeste do Brasil no período de 2016 a 2020.

\section{MÉTODOS}

Trata-se de um estudo descritivo, com análise quantitativa, por meio de dados secundários, no período de 2016 a 2020. Dentre as regiões brasileiras elegeu-se a região nordeste, que é composta por nove estados: Bahia, Pernambuco, Alagoas, Sergipe, Ceará, Rio Grande do Norte, Paraíba, Maranhão e Piauí, com área territorial de $1.554 .000 \mathrm{~km}^{2}$ tendo uma população de 53.081 .950 habitantes. Salienta-se que essa é a região com maior número de estados do país, fazendo com que o Nordeste seja a segunda região mais populosa do país, superada somente pelo Sudeste de acordo com o Instituto de Brasileiro de Geografia e Estatística (IBGE, 2010).

Os dados referentes a cobertura vacinal e o monitoramento rápido de cobertura vacinal 2018 foram coletados no Sistema de Informação em Saúde do Programa Nacional de Imunização (SIPNI). Os casos confirmados de sarampo e óbito foram extraídos do Serviço de Informação ao Cidadão (e-SIC) do Ministério da Saúde e dos boletins epidemiológicos. Para tabulação dos dados e elaboração da tabela e gráficos foi utilizado Microsoft Office Excel e Word 2016. O registro dos dados baseou-se na porcentagem da cobertura vacinal por estado nordestino, bem como o número de casos confirmados de sarampo e óbito de janeiro de 2016 a junho de 2020.

Por utilizar dados secundários, de acesso público, sem identificação de pessoas, este estudo foi dispensado de apreciação por Comitê de Ética em Pesquisa com seres humanos, em conformidade com a Resolução do Conselho Nacional de Saúde, № 466, de 12 de dezembro de 2012 (CONSELHO NACIONAL DE SAÚDE, 2012).

\section{RESULTADOS}

A Cobertura Vacinal (CV) para sarampo no Nordeste $(2016$ - 2020), considerando doses de rotina, encontra-se abaixo do esperado, tanto na primeira dose (D1) como na segunda dose (D2). Para D2 os números são ainda menores, como apresentado na Gráfico 1. 
Gráfico 1 - Cobertura Vacinal em porcentagem (\%) da Tríplice e Tetra Viral em crianças de 1 ano, no Nordeste, de 2016 - 2020

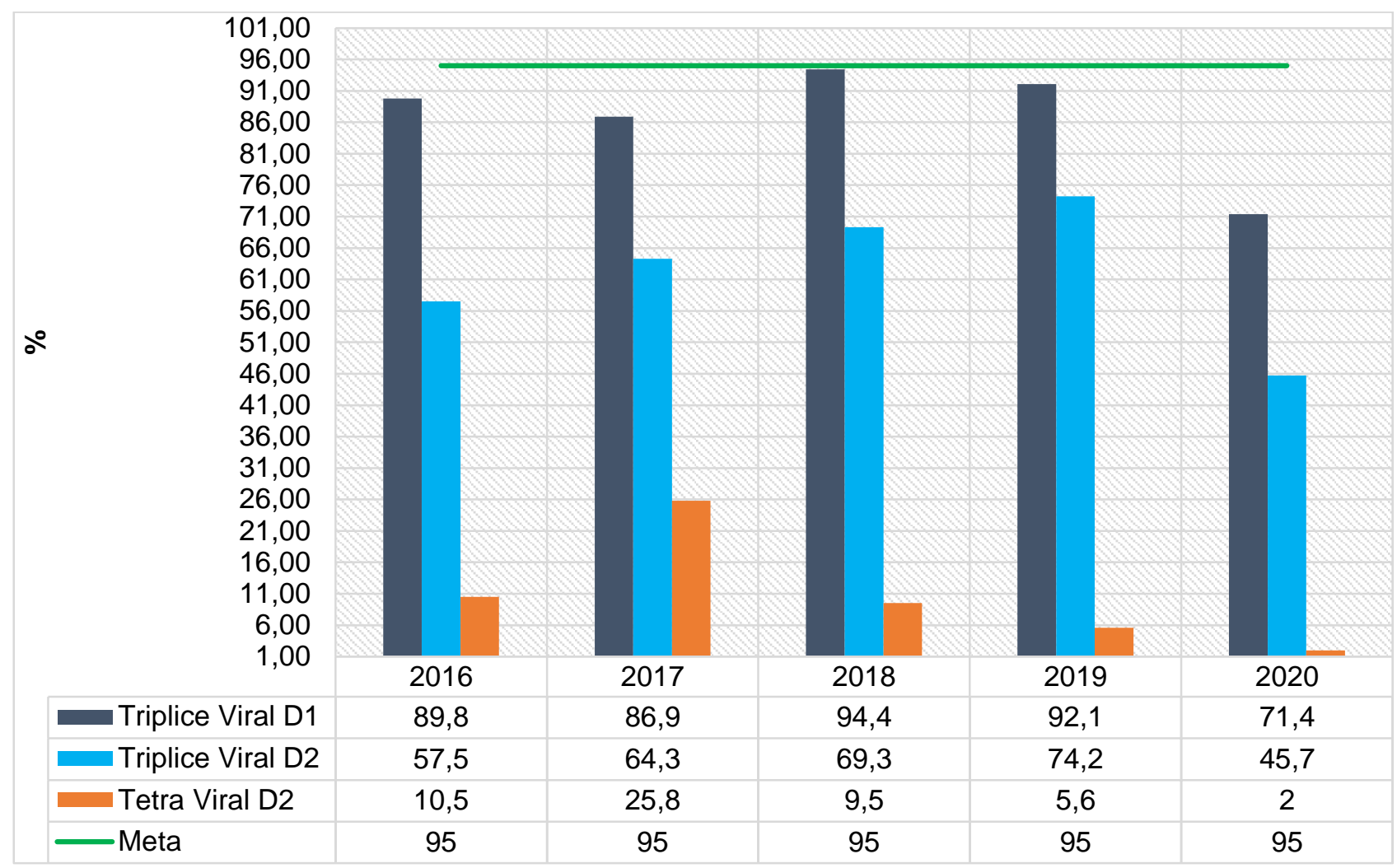

Fonte: Lopes CAS, et al., 2021, dados extraídos do site DATASUS, 2020.

Legenda: *Dados atualizados da vacina tríplice viral e tetra viral até junho de 2020.

Devido ao desabastecimento da Tetra viral em 2016 o PNI designou como esquema vacinal alternativo uma dose de tríplice viral mais uma dose de varicela como D2, então para nível de cobertura soma-se tríplice viral D1 mais a tetra viral. Mesmo levando esse esquema em consideração, as coberturas encontram-se abaixo da meta.

Em 2018 foi realizado o Monitoramento Rápido de Cobertura vacinal após a campanha vacinal indiscriminada para o sarampo em todas as regiões brasileiras, em crianças de 1 a 4 anos. A região nordeste não obteve cobertura homogenia. Sergipe destaca-se com cobertura total acima da meta nas duas doses. $O$ estado de Pernambuco, obteve pior CV, quando comparado aos outros estados do Nordeste. Com relação às faixas etárias as crianças de 2 e 3 anos observa-se que houve cobertura acima de $95 \%$ para D1 em todos os estados nordestinos, como mostra a (Tabela 1). 
Tabela1 - Monitoramento rápido de cobertura vacinal: sarampo, caxumba e rubéola, 2018.

\begin{tabular}{|c|c|c|c|c|c|c|c|c|c|c|c|c|c|c|c|c|c|c|}
\hline \multirow{2}{*}{$\begin{array}{l}\text { Faixa } \\
\text { etária }\end{array}$} & \multicolumn{2}{|c|}{$\begin{array}{c}\text { CV } \\
\text { Bahia }\end{array}$} & \multicolumn{2}{|c|}{$\begin{array}{c}\text { CV } \\
\text { Pernambuco }\end{array}$} & \multicolumn{2}{|c|}{$\begin{array}{c}\text { CV } \\
\text { Alagoas }\end{array}$} & \multicolumn{2}{|c|}{$\begin{array}{c}\text { CV } \\
\text { Maranhão }\end{array}$} & \multicolumn{2}{|c|}{$\begin{array}{c}\text { CV } \\
\text { Paraíba }\end{array}$} & \multicolumn{2}{|c|}{$\begin{array}{c}\text { CV } \\
\text { Ceará }\end{array}$} & \multicolumn{2}{|c|}{$\begin{array}{c}\text { CV } \\
\text { Rio Grande } \\
\text { do Norte } \\
\end{array}$} & \multicolumn{2}{|c|}{$\begin{array}{c}\text { CV } \\
\text { Piauí }\end{array}$} & \multicolumn{2}{|c|}{$\begin{array}{c}\text { CV } \\
\text { Sergipe }\end{array}$} \\
\hline & D1 & D2 & D1 & D2 & D1 & D2 & D1 & D2 & D1 & D2 & D1 & D2 & D1 & D2 & D1 & D2 & D1 & D2 \\
\hline $12-14 m$ & 91,2 & 0,0 & 90,0 & 0,1 & 88,8 & 0,0 & 88,7 & 0,0 & 90,6 & 0,0 & 95,9 & 0,0 & 91,7 & 0,2 & 93,6 & 0,0 & 93,1 & 0,0 \\
\hline $15-23 m$ & 95,0 & 82,6 & 94,3 & 82,0 & 95,5 & 79,9 & 93,4 & 71,2 & 92,4 & 75,9 & 98,2 & 87,0 & 95,0 & 75,7 & 97,1 & 82,7 & 97,7 & 93,0 \\
\hline 2 anos & 95,5 & 87,9 & 95,3 & 88,4 & 95,1 & 85,8 & 95,6 & 81,9 & 96,7 & 89,0 & 98,9 & 91,0 & 96,4 & 83,8 & 97,5 & 91,0 & 97,3 & 95,8 \\
\hline 3 anos & 95,8 & 88,7 & 95,7 & 89,3 & 95,1 & 89,2 & 97,3 & 84,0 & 97,3 & 91,5 & 99,1 & 91,2 & 95,9 & 83,9 & 97,2 & 91,6 & 98,0 & 96,5 \\
\hline 4 anos & 95,7 & 88,7 & 94,1 & 87,4 & 95,5 & 90,3 & 97,7 & 85,6 & 97,1 & 91,8 & 99,1 & 91,0 & 95,5 & 85,1 & 98,2 & 93,0 & 97,8 & 96,3 \\
\hline Total & 94,9 & 87,3 & 94,1 & 87,1 & 94,4 & 86,8 & 95,0 & 81,2 & 95,2 & 87,7 & 98,4 & 90,1 & 94,9 & 82,2 & 96,9 & 89,8 & 97,1 & 95,5 \\
\hline
\end{tabular}

Legenda: $\square$ Cobertura preconizada de 95\% ou mais; $\square$ Cobertura abaixo de 95\%.

Fonte: Lopes CAS, et al., 2021, dados extraídos do site DATASUS, 2020. 
Em relação aos números de casos confirmados de sarampo e óbitos referentes, de janeiro de 2018 a agosto de 2020. O ano de 2019 destaca-se por apresentar maior número de casos confirmados. $O$ estado de Pernambuco apresentou maior número de casos com um total de 268 , sendo também o estado onde houve o único óbito. O estado da Paraíba ocupou o segundo lugar, com 52 casos. Em 2020, Sergipe e Maranhão tiveram aumento de casos em relação a 2019, como mostra o (Gráfico 2).

Gráfico 2 - Distribuição dos casos de sarampo e óbitos confirmados dos Estado do Nordeste, 2018 - 2020*.

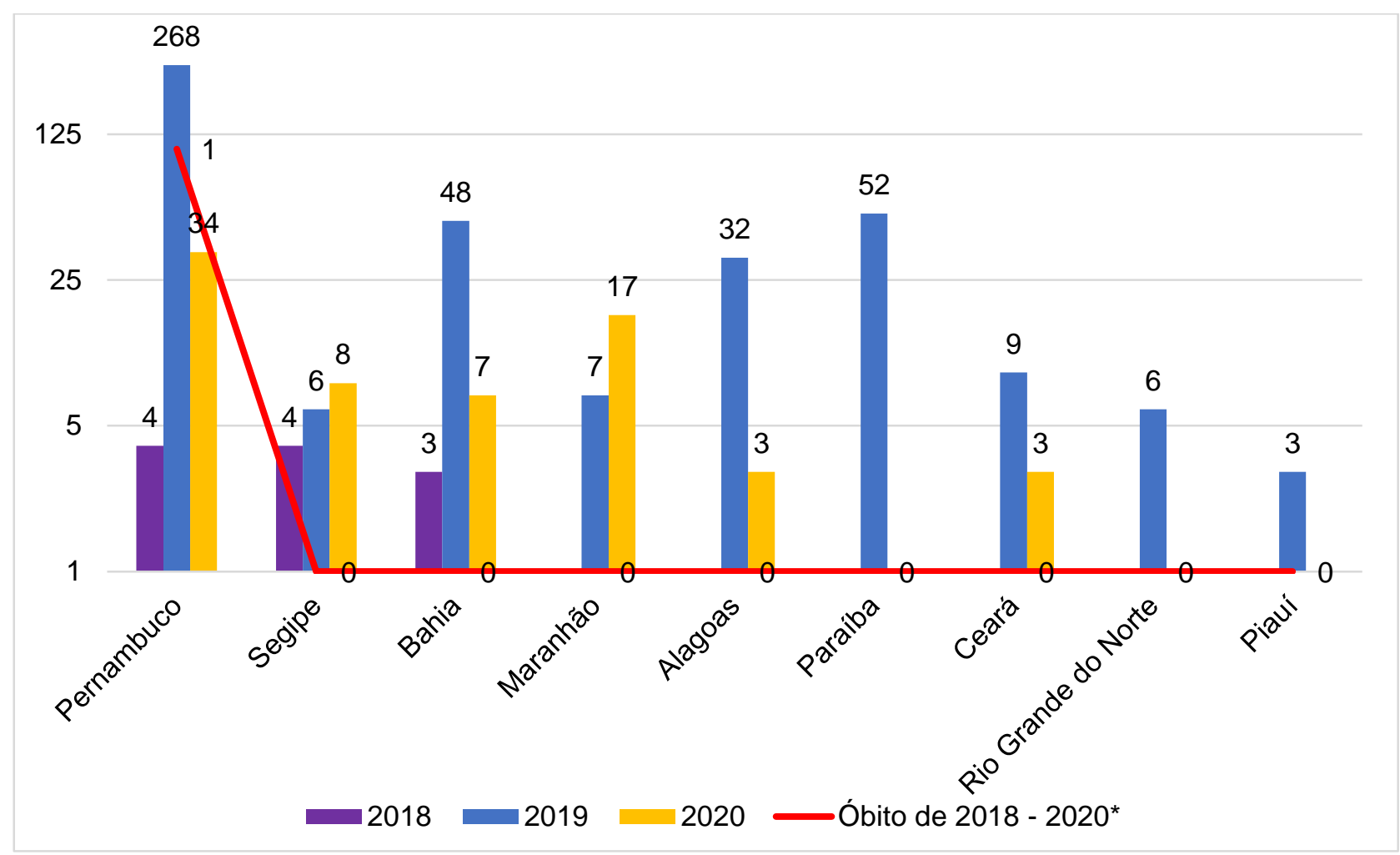

Legenda: *Atualização em 31/08/2020. Dados sujeitos à alteração.

Fonte: Lopes CAS, et al., 2021.

\section{DISCUSSÃO}

Todos os esforços envolvidos pelo SUS para melhor atuar em combate ao sarampo concentra-se na vacinação como forma de prevenção, visto que não há medicação específica para cura. Porém, mesmo existindo uma vacina segura e eficaz disponível para população, o país registra um declínio nas coberturas relacionadas a esse imunobiológico ao longo dos anos (SATO APS, 2018; RODRIGUES BLP, et al., 2020).

Essa realidade também foi evidenciada no presente estudo, visto que os estados da região nordeste, no período de janeiro de 2016 até junho de 2020, não atingiram a meta anual de 95\% para cobertura vacinal com o componente do sarampo, e apenas o estado do Ceará obteve índice significativo de 95,9\% no MRC, como preconiza a OMS.

Um estudo realizado em Salvador na Bahia a fim de avaliar as coberturas vacinais alcançadas por condições socioeconômicas, observou-se que as menores coberturas se concentraram naquelas camadas da população que apresentaram piores condições de vida, e dentre as vacinas ofertadas a cobertura mais baixa são observadas para a tríplice viral em todos os estratos socioeconômico (BARATA RB e PEREIRA SM, 2013).

O MRC é considerado método útil para acompanhamento da CV, pois é realizado a nível local de visita casa a casa, com observação da caderneta do vacinado e na oportunidade também pode ser efetivada a atualização da caderneta de vacinas, bem como descreve as justificativas apresentadas pelos pais/responsáveis pela não vacinação dos filhos (BRASIL, 2018). 
Os resultados do MRC podem subsidiar no processo de estratégia dos gestores e profissionais de saúde para reverter as lacunas que dificultam a vacinação principalmente das crianças, tendo em vista que as coberturas adequadas ajudam na imunidade coletiva beneficiando as outras faixas etárias (MOURA ADA, et al., 2018; TURNER R, 2019; RODRIGUES BLP, et al., 2020).

No MRC a faixa etária de 2 a 3 anos em todos os estados do Nordeste alcançaram a meta preconizada de $95 \%$. Todavia, em relação à completude vacinal com a D1 apenas Sergipe, dos nove estados que compõem a região, conseguiu apresentar índices acima da meta a partir de 2 anos. Possivelmente uma parte destas crianças continuam sem completar a vacinação e por isso, algumas estratégias devem ser adotadas antes do curso de uma epidemia de sarampo, como por exemplo a intensificação das ações de busca ativa das crianças não vacinadas, que consequentemente estão sob o risco de adoecer, sobretudo considerando o período de pandemia da COVID-19 (LASSI ZS, et al., 2021).

Ressalta-se que a pandemia da COVID-19 modificou drasticamente a rotina das pessoas, assim como o uso dos serviços de saúde. Desta forma muitos cuidadores, devido às medidas de distanciamento social e o medo do contagio da COVID-19, deixaram de vacinar suas crianças. Em consequência disso diferentes países incluindo o Brasil tiveram importante redução das taxas de cobertura vacinal entre crianças, sendo marcante a faixa etária inferior dos dois anos (SATO APS, 2020).

Salienta-se ainda que no ano de 2017 e no início de 2018 o Brasil sofreu com o desabastecimento da vacina tríplice e tetra viral (MINISTÉRIO DA SAÚDE, 2018; MINISTÉRIO DA SAÚDE, 2020). No entanto, a região nordeste já estava em uso da tríplice viral mais varicela, como esquema alternativo para tetra viral, e ainda assim não estava nos padrões de $95 \%$ como preconiza OMS. Salienta-se que a falta do imunobiológico coloca em risco a credibilidade do serviço e diminui a procura da população pela vacina (ARAÚJO MCG, et al., 2020).

Estudo realizado no Maranhão em 2016, em unidades básicas de saúde, também revelou que entre os fatores elencados para não completude do esquema vacinal estava à falta de vacinas $(88,0 \%)$, ausência de seringas descartáveis $(75 \%)$ e a falta de caderneta de vacinação da criança (12\%) sem está última impossibilita a vacinação pois é nela que é colocado o nome da vacina, o lote, a data de validade, a assinatura e registro do profissional da vacina administrada e o aprazamento das próximas vacinas a ser aplicada (ARAÚJO MCG, et al., 2020).

Outras razões para não vacinação de crianças já bem documentadas na literatura são: preocupações com eventos adversos graves; o número de vacinas dadas simultaneamente e nos primeiros 2 anos de vida; a crença de que as vacinas podem causar deficiência, tais como o autismo percepção de que os ingredientes que compõe a vacina podem não ser seguro e que as vacinas não são testadas suficiente para validação da sua segurança (SALMON DA, et al., 2015).

Complementando, Cardoso MDT, et al. (2015), destacam alguns motivos para não vacinação no grupo infantil: esquecimento, dificuldade de acesso, doença na criança ou pelos pais/cuidadores optarem por não realizar a vacinação. Esses achados confirmam a importância de manutenção da ESF funcionado diariamente, de que seja aproveitado cada ida do usuário a procura de qualquer serviço de saúde, a exigência da caderneta de vacinação e de inclusive referenciá-lo à sala de vacina para atualização, quando necessário.

Os resultados da pesquisa de Corrêa SMC, et al. (2021) sinalizam os possíveis motivos da queda da imunização, quais sejam: a falta de tempo dos pais em levar seus filhos as Unidades básicas de Saúde para vacinar, além do temor das mães quanto a dor que seus filhos podem sofrer no momento da administração das vacinas.

Em revisão sistemática recente apresenta uma síntese de estudos qualitativos que exploram as opiniões e experiências dos pais para vacinação na infância. Assim, os principais achados foram de que as publicações se concentram na vacina contra sarampo, caxumba, rubéola e de que a comunicação tem influência nas decisões dos pais e cuidadores em relação à vacinação infantil (AMES HMR, et al., 2017).

Outra causa que contribui para a redução da cobertura do sarampo está associada ao fato de os indivíduos não ver com frequência óbitos e sequelas ocasionadas pela patologia, com isso perde a noção de perigo e 
muitas vezes adiam ou deixa de vacinar seus entes queridos (DOMINGUES CMAS, et al., 2019). Sato APS (2018) e Domingues CMAS, et al. (2020) enfatiza também que entre as justificativas para não vacinar está a baixa percepção do risco da doença, visto que na visão dos pais elas já estão controladas ou são leves, alguns pais também têm desconfiança em relação as tecnologias médicas, resistência autoridade governamental, persuasão a abordagens e problemas operacionais na administração de vacinas.

Para que se compreenda a dimensão da aceitação das vacinas na infância, devem ser consideradas as percepções de pais e cuidadores, a fim de compreender os pontos de vista de todas as pessoas envolvidas na tomada de decisões sobre a saúde de uma criança. Sabe-se também que em diferentes países, grupos anti-vacinas, comunidades religiosas e pais com informações equivocadas, tem incentivado a não vacinação do grupo infantil, através da utilização das redes sociais para socialização de informações falsas, onde estabelecem relação entre a vacina e eventos adversos considerados graves (MIZUTA AH, et al., 2019); MEDEIROS EAS, 2020).

Os mitos relacionados às vacinas, informações pseudocientíficas, relação temporal com eventos adversos, são outras barreiras, vinculadas, principalmente aos movimentos antivacina (LEVI GC, 2013). Sabe-se que entre os efeitos causados pela disseminação de notícias falsas e consequente diminuição na confiança das vacinas estão relacionadas ao recrudescimento das doenças controladas e epidemias como do sarampo (SALMON DA, et al., 2015).

Um estudo realizado por Trentini $F$, et al. (2019) em países europeus, motivado pela baixa cobertura vacinal, mostrou uma estratégia utilizada pela França e Itália que tornou obrigatório a vacinação para 0 sarampo nas escolas, exigindo que os pais vacinem seus filhos para que possam frequentá-la.

No Brasil, temos a lei federal de 1975, que dispõe sobre a organização das ações de vigilância epidemiológica e o Programa Nacional de Imunizações, estabelecendo no parágrafo 27 que a vacinação é obrigatória em todo o território nacional. Inclusive o decreto dessa lei, constitui como dever de todo cidadão submeter-se, e os menores dos quais tenha a guarda ou responsabilidade, à vacinação obrigatória (BRASIL, 1986).

Além disso, o Estatuto da Criança e do Adolescente (ECA) determina que cabe a família garantir os direitos à saúde desses, dentre esses direitos destaca-se as vacinas do calendário nacional de vacinação. $A$ efetivação do estatuto deve ser fiscalizada e os pais/responsáveis orientados sobre direitos e deveres das crianças e adolescentes, o que inclui a administração das vacinas desde o nascimento (BRASIL, 1990).

Sabe-se que manter cobertura vacinal elevada, interrompe cadeia de transmissão das doenças infectocontagiosas, sobretudo o sarampo. Em relação a região a nordeste que apresentou cobertura vacinal baixa nos anos de 2016 e 2017 sem registro de casos, tal falto, não deve ser negligenciado e a elevação da cobertura vacinal deve ser incentivada, visto que, no ano de 2019, como mostra a (Gráfico 2) a região nordeste obteve o maior número de casos confirmados do sarampo.

Chaves ECR, et al. (2019), reforçam em seu estudo que são necessárias as seguintes medidas para conter o avanço da circulação do vírus do sarampo: notificação de casos suspeitos em 24 horas, investigação ágil com bloqueio vacinal, vacinação de indivíduos que tenha contato direto com o caso confirmado, avaliações e monitoramento constantes das coberturas vacinais e surtos, intensificação da vacinação no ambiente escolar, a fim de desenvolver estratégias que contemplem à melhoria e ampliação das medidas de prevenção e controle.

Sobre a atualização da vacinação de escolares, salienta-se que um grande aliado é o Programa Saúde na Escola, bem como as ações de educação em saúde realizadas nos diferentes níveis de atenção à saúde. Todavia, para que o programa seja efetivo faz-se necessário o empenho da equipe de saúde, inclusive dos gestores escolares e professores, como também a participação dos pais/responsáveis (MINISTÉRIO DA SAÚDE, 2017). Conta-se também com o protagonismo dos Agentes Comunitários de Saúde, que realizando visitas domiciliares fazem orientações para os pais/cuidadores sobre as medidas de prevenção e promoção da saúde, além de acompanharem o esquema vacinal e aprazamento das vacinas subsequentes (BRASIL, 2018). 


\section{CONCLUSÃO}

Identificou-se que a cobertura vacinal na região nordeste com o componente sarampo do Brasil, no período de 2016 a 2020, foi inferior as metas propostas pela OMS e pelo Programa Nacional de Imunização. O ano de 2019 se destacou com as maiores taxas de casos de sarampo confirmados, sendo Pernambuco o estado com maior número. Os resultados do MRC enfatizam a falta de homogeneidade da cobertura vacinal para o sarampo nos estados do Nordeste, cenário preocupante, pois o sarampo configura-se como uma doença de alta transmissibilidade e em alguns casos podendo ser letal. Isso reflete a necessidade de incorporação de estratégias que visem a ampliação da cobertura vacinal de forma oportuna e assertiva a fim de reduzir os bolsões de pessoas não vacinadas e eliminar sua transmissão.

\section{REFERÊNCIAS}

1. AMES HMR, et al. Parent's and informal caregivers' views and experiences of communication about routine childhood vaccination: a synthesis of qualitative evidence. Cochrane Database of Syst. Rev., 2017; 2(2): CD011787.

2. ARAÚJO MCG, et al. Fatores que interferem no cumprimento do calendário vacinal na infância. Revista Eletrônica Acervo Saúde, 2020; (42): e2874.

3. BARATA RB, PEREIRA SM. Desigualdades sociais e cobertura vacinal na cidade de Salvador, Bahia. Revista Brasileira de Epidemiologia, 2013; 16 (2): 266-277.

4. BRASIL. Estatuto da Criança e do Adolescente. 1990. Lei № 8.069. Disponível em: http://www.planalto.gov.br/ccivil_03/leis//8069.htm. Acessado em: 10 de maio de 2020.

5. BRASIL. Dispõe sobre a reformulação das atribuições, a jornada e as condições de trabalho, o grau de formação profissional, os cursos de formação técnica e continuada e a indenização de transporte dos profissionais Agentes Comunitários de Saúde e Agentes de Combate às Endemias. 2018. Lei № 13.595. Disponível em: http://www.planalto.gov.br/ccivil_03/_ato2015-2018/2018/lei/L13595.htm. Acesso em: 20 de janeiro de 2020.

6. BRASIL. Dispõe sobre a organização das ações de Vigilância Epidemiológica, sobre o Programa Nacional de Imunizações, estabelece normas relativas à notificação compulsória de doenças, e dá outras providências. Lei №. $6259 . \quad$ Disponível em: http://www.planalto.gov.br/ccivil_03/leis/l6259.htm\#: :text=L6259\&text=LEl\%20No\%206.259\%2C\%20DE\%2030\%20 DE\%20OUTUBRO\%20DE\%201975.\&text=Disp\%C3\%B5e\%20sobre\%20a\%20organiza\%C3\%A7\%C3\%A30\%20das, doen\%C3\%A7as\%2C\%20e\%20d\%C3\%A1\%20outras\%20provid\%C3\%AAncias. Acessado em: 15 de maio de 2020.

7. CARDOSO MDT, et al. Avaliação da cobertura vacinal em crianças de 2 meses a 5 anos na estratégia saúde da família. Rev. APS, 2015; 18(3): $273-280$.

8. CHAVES ECR, et al. Avaliação da cobertura vacinal do sarampo no período de 2013-2019 e sua relação com a reemergência no Brasil. Revista Eletrônica Acervo Saúde, 2020; 38: e1982.

9. CONSELHO NACIONAL DE SAÚDE. Resolução do Conselho Nacional de Saúde. 2012. ํo 466. Disponível em: https://conselho.saude.gov.br/resolucoes/2012/Reso466.pdf. Acesso em: 30 de janeiro de 2019.

10. CORRÊA SMC, et al. As possíveis causas da não adesão à imunização no Brasil: uma revisão de literatura. Revista Eletrônica Acervo Saúde, 2021; 13(4): e7030.

11. DOMINGUES CMAS, et al. Vacina Brasil e estratégias de formação e desenvolvimento em imunizações. Epidemiologia e Serviços de Saúde, 2019; 28(2).

12. DOMINGUES CMAS, et al. 46 anos do Programa Nacional de Imunizações: uma história repleta de conquistas e desafios a serem superados. Cad Saúde Pública, 2020; 36(2): e00222919.

13. INSTITUTO BRASILEIRO DE GEOGRAFIA E ESTATÍSTICA (IBGE). Diretoria de Pesquisas, Coordenação de População e Indicadores Sociais, Estimativas da população residente com data de referência 1ำ de julho de 2019. Disponível em: https://www.ibge.gov.br/geociencias/organizacao-do-territorio/divisao-regional/15778-divisoesregionais-do-brasil.html?=\&t=acesso-ao-produto. Acesso em: 20 de janeiro de 2020.

14. LASSI ZS, et al. The Impact of the COVID-19 Pandemic on Immunization Campaigns and Programs: A Systematic Review. Int. J. Environ. Res. Public Health, 2021; 18, 988.

15. LEVI GC. Recusa de vacinas: causas e consequências. São Paulo: Segmento Farma, 2013; $11 \mathrm{p}$.

16. MEDEIROS EAS. Entendendo o ressurgimento e o controle do sarampo no Brasil. Acta paul. enferm., 2020; 33: eEDT20200001.

17. MOURA ADA, et al. Monitoramento Rápido de Vacinação na prevenção do sarampo no estado do Ceará, em 2015. Epidemiologia e Serviços de Saúde, 2018; 27(2).

18. MINISTÉRIO DA SAÚDE. Secretaria de Vigilância em Saúde. Boletim Epidemiológico 02. Informe semanal sarampo. 2020. Disponível em: https://antigo.saude.gov.br/images/pdf/2020/August/31/Boletim-epidemiologico-SVS-34.pdf. Acessado em: 30 de novembro de 2020.

19. MINISTÉRIO DA SAÚDE. Política Nacional de Atenção Integral à Saúde da Criança. Portaria № 1.130. 2015. Disponível em: https://bvsms.saude.gov.br/bvs/saudelegis/gm/2015/prt1130_05_08_2015.html. Acessado em: 05 de julho de 2020. 
20. MINISTÉRIO DA SAÚDE. 2017. Portaria Interministerial № 1.055. Redefine as regras e os critérios para adesão ao Programa Saúde na Escola - PSE. Disponível em: http://bvsms.saude.gov.br/bvs/saúde legis/gm/2017/pri1055_26_04_2017.html. Acesso em: 20 de janeiro de 2020.

21. MINISTÉRIO DA SAÚDE. Informa mudanças no Calendário Nacional de Vacinação. 2018. Disponível em: https://saude.es.gov.br/Media/sesa/Imuniza\%C3\%A7\%C3\%A3o/SEI_MS\%20\%20Nota\%20Informativa\%20135\%20 \%20mudancas\%20no\%20calendario\%20nacional\%20de\%20vacinacao\%202018.pdf. Acessado em: 15 de julho de 2020.

22. MINISTÉRIO DA SAÚDE. Protocolo de Monitoramento Rápido de Cobertura pós-campanha de vacinação contra

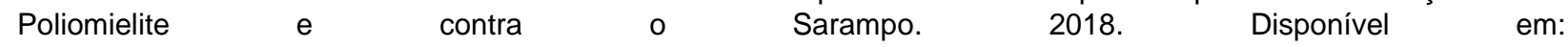
https://www.saude.go.gov.br/images/imagens_migradas/upload/arquivos/2019-01/protocolo-mrc-polio-e-sarampo2018.pdf. Acessado em: 05 de janeiro de 2020.

23. MINISTÉRIO DA SAÚDE. Guia de vigilância epidemiológica em Saúde. 2019. Disponível em: http://portalarquivos2.saude.gov.br/images/pdf/2019/junho/25/guia-vigilancia-saudevolume-unico-3ed.pdf. Acessado em: 10 de novembro de 2020.

24. MINISTÉRIO DA SAÚDE. 2019. Nota informativa no 173/2019. Disponível em: http://www.dive.sc.gov.br/conteudos/publicacoes/Nota_Informativa_N\%C2\%BA173.pdf. Acessado em: 15 de julho de 2020.

25. MIZUTA AH, et al. Percepções acerca da importância das vacinas e da recusa vacinal numa escola de medicina. Rev. Paul. Pediatr., 2019; 37(1): 34-40.

26. PACHECO FC, et al. Measles-containing vaccines in Brazil coverage, homogeneity of coverage and associations with contextual factors at municipal level. Vaccine, 2020; 38(8): 1881- 7.

27. RODRIGUES BLP, et al. Atualizações sobre a imunização contra o sarampo no Brasil: uma revisão sistemática. Revista Eletrônica Acervo Saúde, 2020; (55): e3919.

28. SATO APS. Qual a importância da hesitação vacinal na queda das coberturas vacinais no Brasil? Rev. Saúde Pública, 2018; 52-96.

29. SATO APS. Pandemia e coberturas vacinais: desafios para o retorno às escolas. Rev. Saúde Pública. 2020; 54(115).

30. SALMON DA, et al. Vaccine hesitancy: causes, consequences, and a call to action. Vaccine, 2015; 33: D66-71.

31. ORGANIZAÇÃO PAN-AMERICANA DA SAÚDE (OPAS). Sarampo, folha informativa. Brasília. 2019. Disponível em: https://www.paho.org/pt/topicos/sarampo. Acesso em: 12 de dezembro de 2020.

32. ORGANIZAÇÃO PAN-AMERICANA DA SAÚDE (OPAS). Imunização. Disponível em: https://www.paho.org/pt/topicos/imunizacao. Acesso em: 15 de julho de 2021.

33. TRENTINI F, et al. The introduction of 'No jab, No school' policy and the refinement of measles immunization strategies in high-income countries BMC Medicine, 2019; 17: 86.

34. TURNER R, on behalf of the PLOS Medicine Editors (2019) Measles vaccination: A matter of confidence and commitment. PLoS Med., 2019; 6(3): e1002770. 